\title{
The short term burden of ambient fine particulate matter on chronic obstructive pulmonary disease in Ningbo, China
}

\author{
Guoxing $\mathrm{Li}^{1 \dagger}$, Jing Huang ${ }^{1 \dagger}$, Guozhang $X \mathrm{u}^{2}$, Xiaochuan Pan ${ }^{1}$, Xujun Qian ${ }^{3}$, Jiaying Xu ${ }^{4}$, Yan Zhao ${ }^{1}$, Tao Zhang ${ }^{2}$, \\ Qichen Liu', Xinbiao Guo ${ }^{1}$ and Tianfeng He 2* $^{*}$
}

\begin{abstract}
Background: Numerous studies have found associations between ambient fine particulate matter $\left(\mathrm{PM}_{2.5}\right)$ and increased mortality risk. However, little evidence is available on associations between $\mathrm{PM}_{2.5}$ and years of life lost (YLL). We aimed to estimate the YLL due to chronic obstructive pulmonary disease (COPD) mortality related to ambient PM $_{2.5}$ exposure.

Methods: A time-series study was conducted based on the data on air pollutants, meteorological conditions and 18,472 registered COPD deaths in Ningbo, China, 2011-2015. The effects of PM 2.5 on YLL and daily death of COPD were estimated, after controlling long term trend, meteorological index and other confounders.

Results: The impact of $\mathrm{PM}_{2.5}$ on YLL due to COPD lasted for 5 days (lag $0-4$ ). Per $10 \mu \mathrm{g} / \mathrm{m}^{3}$ increase in $\mathrm{PM}_{2.5}$ was associated with 0.91 (95\%Cl: 0.16, 1.66) years increase in YLL. The excess YLL of COPD mortality were 8206 years, and 0.38 day per person in Ningbo from 2011 to 2015. The exposure-response curve of PM 2.5 and YLL due to COPD showed a non-linear pattern, with relatively steep at low levels and flattened out at higher exposures.. Furthermore, the effects were significantly higher in the elderly than those in the younger.
\end{abstract}

Conclusions: Our findings explored burden of $\mathrm{PM}_{2.5}$ on YLL due to COPD and highlight the importance and urgency of ambient $\mathrm{PM}_{2.5}$ pollution control and protection of the vulnerable populations.

Keywords: Fine particulate matter $\left(\mathrm{PM}_{2.5}\right)$, Years of life lost, Chronic obstructive pulmonary disease, Modifications, Exposure-response curve

\section{Background}

Ambient fine particulate matter $\left(\mathrm{PM}_{2.5}\right)$ is one of the most important environmental issues worldwide, and the adverse impact of $\mathrm{PM}_{2.5}$ has become a great concern. Many epidemiological studies have provided evidences of associations between $\mathrm{PM}_{2.5}$ exposure and excess mortality [1-3]. The majority of these studies had estimated excess mortality using daily death counts as the dependent variable. However, using this indicator might ignore the differences in ages of deaths [4]. From a public health perspective, deaths occurring at different ages are not equally important.

\footnotetext{
* Correspondence: hetf@nbcdc.org.cn

'Equal contributors

${ }^{2}$ Ningbo Municipal Center for Disease Control and Prevention, Haishu

District, 237 Yongfeng Road, Ningbo 315010, China

Full list of author information is available at the end of the article
}

Years of life lost (YLL) is a measure of disease burden that considers the life expectancy at death and, therefore, assigns higher weights to deaths that occur at younger ages [5]. Besides, it is more accurate than mortality to measure premature death and excess mortality [6]. In this sense, exploring the relationships between $\mathrm{PM}_{2.5}$ and YLL may provide additional information for policy making and health resource allocation, and has important public health significance.

Chronic obstructive pulmonary disease (COPD), characterized by irreversible airflow obstruction, is a common chronic respiratory disease [7]. Due to the slow progression and chronic nature of the disease, COPD represents a massive and growing disease burden and is an important cause of morbidity and mortality [8]. The Global Burden of Disease study showed that COPD was the third leading cause of deaths in the world and 
ranked the ninth of global YLL in 2010 [9]. There is compelling evidence that short-term exposure to particulate matter is a risk factor for the development and exacerbation of COPD [10-13]. However, the availability of studies on the associations between ambient $\mathrm{PM}_{2.5}$ and YLL of COPD is rare up to now, and the modifications of socioeconomic factors such as age, gender and marital status are unclear.

With the rapid development in industrialization and urbanization, ambient $\mathrm{PM}_{2.5}$ pollution has aggravated in China in recent years. Ningbo, located in the Yangtze River Delta in the southern China, is the world's fourthlargest port city. The population in Ningbo was estimated to be 7.83 million in 2015, distributed in an area of approximately $9816 \mathrm{~km}^{2}$. The high level of economic development in the city also caused the ambient $\mathrm{PM}_{2.5}$ pollution to be a subject of highly concern.

In this study, we conducted a time-series study to explore the disease burden of COPD from short term ambient $\mathrm{PM}_{2.5}$ exposure in Ningbo, China, 2011-2015, using the indicator of YLL..

\section{Methods}

\section{Data on mortality and YLL}

Daily mortality data on deaths of COPD between January 1st 2011 and December 31th 2015 were obtained from Ningbo Municipal Center for Disease Control and Prevention, and the data was restricted to registered residents only. COPD deaths were identified according to the International Classification of Diseases 10th version (ICD-10: J40-44). The dataset comprised date of death, gender, age and marital status. Daily death count was defined as the number of deaths occurring on a single day.

We calculated YLL by matching the patient's age to the life table for each death. The sex- and age-group specific life expectancy of Chinese population was obtained from the World Health Organization (WHO), and life expectancies for 2011-2015 were averaged (Additional file 1: Table S1). Daily YLL were calculated by summing the YLL for all deaths on the same day. Both daily YLL and deaths counts were stratified by age ( $<75$ and $\geq 75$ years), gender (male and female) and marital status (the married and the widowed).

\section{Exposure assessment}

Concentrations of $\mathrm{PM}_{2.5}$, inhalable particulate matter $\left(\mathrm{PM}_{10}\right)$, sulfur dioxide $\left(\mathrm{SO}_{2}\right)$ and nitrogen dioxide $\left(\mathrm{NO}_{2}\right)$ were monitored continuously at 11 monitoring sites which cover urban and suburban areas of Ningbo. The concentrations of the air pollutants were measured according to the Chinese National Ambient Air Quality Standard [14]. The Environment Monitoring Center of Ningbo collects the pollutants concentrations from all the monitoring sites of the city and records the hourly concentrations, from which the daily average levels for all the individual monitoring sites and the whole city levels were derived. Number of missing is less than $1 \%$, and the missing values were substituted with the mean daily value. Daily meteorological data, including temperature and relative humidity, were obtained from the Ningbo Meteorological Bureau.

\section{Statistical analysis}

We used generalized additive model (GAM) to explore the impacts of particulate matter on YLL. Because the dependent variable of daily YLL follows a normally distributed (Additional file 1: Figure S1), the family function for GAM was Gaussian.

The model is as follows:

$$
\mathrm{YLLt}=\alpha+\sum_{i=1}^{q} \beta \mathrm{i}(\mathrm{Xi})+\sum_{j=1}^{p} \mathrm{fj}(\mathrm{Cj}, \mathrm{df})+\mathrm{Wt}(\text { week })
$$

In the model, $Y L L_{t}$ is the observed daily YLL at day $t ; \alpha$ is the intercept; $\beta$ is the coefficients of YLL associated with per $1 \mu \mathrm{g} / \mathrm{m}^{3}$ increase in particulate matter; $X i$ is the daily mean concentrations of particulate matter; $C j$ is the confounding factors including time, daily temperature, daily relative humidity; $f_{j}$ is the smooth functions (natural cubic spline); $W_{t}$ (week) is the dummy variables for day of week on day $t$. We applied the penalized spline function of time and 7 degrees of freedom per year was used to control for secular trend and seasonality. Degrees of freedom for temperature and relative humidity were set to 3 according to the previous studies $[15,16]$. Considering the lagging effects of temperature, the 14-day moving average of temperature was used. For relative humidity, the average value of the present day was used in the models.

Then, to investigate the lag pattern of $\mathrm{PM}_{2.5}$, potentially delayed and cumulative associations were estimated. We first examined the delayed associations using a single day lag (from lag0 to lag7), as previous studies showed the lag effects of particulate matter were strongest within 7 days $[2,17]$. Then the cumulative associations were estimated using the moving average over the lag periods from lag01 (moving average concentrations of day 0 and day 1 ) to lag07 (moving average concentrations of day0 to day7). Final results were presented as changes in daily YLL with per $10 \mu \mathrm{g} / \mathrm{m}^{3}$ increase in $\mathrm{PM}_{2.5}$ in different lag days. Considering the $\mathrm{PM}_{2.5}$ effect of 5-day moving average concentrations from day 0 to day 4 (lag04) is strongest, so we use lag04 in our main analysis.

We also calculated the excess YLL as follows:

$$
\text { YLL of COPD advanced by PMt }=\sum_{t=1}^{1826} \mathrm{PMt} \times \beta
$$

Where PMt is the concentrations of $\mathrm{PM}_{2.5}$ (lag04) in our main studies at day $\mathrm{t}, \beta$ is the value of $1 \mu \mathrm{g} / \mathrm{m}^{3}$ particulate matter increase. 
Secondly, we used the penalized spline of $\mathrm{PM}_{2.5}$ to replace the linear variable of $\mathrm{PM}_{2.5}$ to plot the doseresponse curve of $\mathrm{PM}_{2.5}$ and YLL (Fig. 3). The relationship appeared to be nonlinear and the curve became flattening in high level $\mathrm{PM}_{2.5}$ concentration days, so we detected the turning point. The Akaike Information Criterion (AIC) values of GAM models using 1 unit increment in $\mathrm{PM}_{2.5}$ within the identified range of threshold were computed between $100 \mu \mathrm{g} / \mathrm{m}^{3}$ and $150 \mu \mathrm{g} / \mathrm{m}^{3}$ (Additional file 1: Table S2). The concentration of $\mathrm{PM}_{2.5}$ with the lowest AIC value was selected as the turning point. Similar method had been used in previous studies [18-20]. According to the turning point $\left(128 \mu \mathrm{g} / \mathrm{m}^{3}\right)$, we created two variables (high concentration level, low concentration level), which were higher or lower than the turning point respectively, to explore the piecewise linear association of $\mathrm{PM}_{2.5}$.

In addition, the analyses were stratified by age, gender and marital status. Single pollutant model was used to explore the main association of $\mathrm{PM}_{2.5}$ with daily YLL, while two pollutants models with $\mathrm{SO}_{2}$ or $\mathrm{NO}_{2}$ added was used to examine the stability of these associations. In order to have a comparison, we also examined the effects of $\mathrm{PM}_{10}$.

Furthermore, we evaluated the impacts of particulate matter on daily death counts of COPD. The independent variable, lag structure and relevant degrees of freedom in the model were similar to those in YLL model, except time series function with the Poisson link under a GAM framework was used because the dependent variable daily death counts following a Poisson distribution. Results were presented as changes in excess risk (ER) of deaths from COPD per $10 \mu \mathrm{g} / \mathrm{m}^{3}$ increase in $\mathrm{PM}_{2.5}$ and $\mathrm{PM}_{10}$ in different lag days. The equation of ER was as follows:

$$
\mathrm{ER}=\left(e^{10 \times \beta}-1\right) \times 100 \%
$$

In the equation, $\beta$ is the value of daily death counts associated with a unit increase in particulate matter.

An autocorrelation function (ACF) was used in the models to assess whether the residuals were independent over time and the reliability of the models. The results showed no obvious autocorrelations were found (Additional file 1: Figure S2 to Figure S5). Sensitivity analyses were performed on the parameters included in the models to test the robustness of our results. We tested using 4 of degrees of freedom of relative humidity, 4 of degrees of freedom of temperature, and used 6 \& 8 of degrees of freedom of time per year in the models.

In this study, the mgcv packages in $\mathrm{R}$ software (Version 3.1.2) were used to perform the analyses. $P<0.05(2$ side) were considered to be significant. The study was approved by the Institutional Review Board of Ningbo Municipal Center for Disease Control and Prevention (No. IRB 201603).

\section{Results}

Mean daily concentrations of $\mathrm{PM}_{2.5}$ and $\mathrm{PM}_{10}$ were $49.58 \mu \mathrm{g} / \mathrm{m}^{3}$ and $78.59 \mu \mathrm{g} / \mathrm{m}^{3}$, respectively during 2011 to 2015 in Ningbo, China (Table 1). Correlations between air pollutants and meteorological conditions were examined by Spearman correlation function and presented in Table 2. Particulate and gaseous pollutant and meteorological conditions were correlated with each other, with the most significant correlations observed between the four air pollutants.

A total of 18,472 registered COPD deaths were identified for the five study years. Daily death counts and YLL of COPD had a mean of 10 and 80 years, respectively. The average daily YLL of the elderly, male and the married ones were higher than that of the young, female and the widowed ones, respectively (Table 1). Both outcomes showed a seasonal trend, with higher values in November through the next April than other months (Fig. 1).

Estimated changes with 95\% confidence intervals in YLL due to COPD associated with $10 \mu \mathrm{g} / \mathrm{m}^{3}$ increase in $\mathrm{PM}_{2.5}$ in different lag days were presented in Fig. 2. In general, the associations with $\mathrm{PM}_{2.5}$ lasted for five days (lag0 to lag4), and gradually reduced after day 4. From day 5 to day 7 , the effects had no significance. In addition, the lag patterns were similar for YLL and ER.

The strongest associations were found in 5-day moving average concentrations from day 0 to day 4 (lag04). In single pollutant model, a $10 \mu \mathrm{g} / \mathrm{m}^{3}$ increase in $\mathrm{PM}_{2.5}$ was associated with $0.91(95 \%$ CI: $0.16,1.66)$ years increase in YLL, and 1.32\% (95\%CI: 0.52\%, 2.12\%) increase in ER for COPD deaths, respectively.

We also analyzed the associations of $\mathrm{PM}_{10}$ in our study. Per $10 \mu \mathrm{g} / \mathrm{m}^{3}$ increase in $\mathrm{PM}_{10}$ was associated with 0.81 (95\%CI: $0.30,1.33)$ years increase in YLL and 1.07\% (95\%CI: $0.51 \%, 1.63 \%)$ increases in ER of COPD death at lag04.

Furthermore, the excess YLL of COPD mortality in Ningbo from 2011 to 2015 were estimated, which were 8206 years. Take the population of Ningbo into consideration, the YLL in days per person of the population for a 365 day period of exposure was nearly 0.38 day per person in Ningbo from 2011 to 2015.

In addition, the exposure-response curve of $\mathrm{PM}_{2.5}$ and YLL due to COPD showed a non-linear pattern (Fig. 3). When stratified by the turning point of $\mathrm{PM}_{2.5}$, the associations below the turning point concentration were stronger than those above the turning point concentration (Table 3). Specially, the associations of $\mathrm{PM}_{2.5}$-YLL due to COPD was 1.44 (95\%CI: 0.57, 2.32) below the turning point concentration, while the value was 0.32 (95\%CI:-0.59, 1.23) above the turning point concentration. And the mean age at death for $\mathrm{PM}_{2.5}$ concentrations above and below the median are 74.50 
Table 1 Daily weather conditions, YLL and death counts of COPD in Ningbo, China, 2011-2015

\begin{tabular}{|c|c|c|c|c|c|c|}
\hline Variables & Mean \pm SD & Minimum & 25th & Median & 75th & Maximum \\
\hline $\mathrm{PM}_{2.5}\left(\mu \mathrm{g} / \mathrm{m}^{3}\right)$ & $49.58 \pm 32.36$ & 5.86 & 28.25 & 41.73 & 61.25 & 421.71 \\
\hline $\mathrm{PM}_{10}\left(\mu \mathrm{g} / \mathrm{m}^{3}\right)$ & $78.59 \pm 48.19$ & 12.86 & 44.94 & 66.33 & 97.97 & 543.88 \\
\hline $\mathrm{SO}_{2}\left(\mu \mathrm{g} / \mathrm{m}^{3}\right)$ & $21.34 \pm 13.84$ & 5.38 & 12.14 & 16.94 & 25.73 & 112.6 \\
\hline $\mathrm{NO}_{2}\left(\mu \mathrm{g} / \mathrm{m}^{3}\right)$ & $43.41 \pm 18.65$ & 7.62 & 30.12 & 40.61 & 55 & 121.8 \\
\hline Temperature $\left({ }^{\circ} \mathrm{C}\right)$ & $17.49 \pm 8.94$ & -1.67 & 10 & 18.89 & 24.44 & 34.44 \\
\hline Relative humidity (\%) & $76.41 \pm 12.25$ & 31 & 68 & 77 & 86 & 100 \\
\hline \multicolumn{7}{|l|}{ Years of life lost (years) } \\
\hline Total & $80 \pm 40$ & 0 & 51 & 73 & 102 & 278 \\
\hline Age $<75$ years & $19 \pm 20$ & 0 & 0 & 13 & 30 & 136 \\
\hline Age $\geq 75$ years & $61 \pm 30$ & 0 & 39 & 55 & 77 & 227 \\
\hline Male & $46 \pm 27$ & 0 & 26 & 42 & 62 & 174 \\
\hline Female & $34 \pm 22$ & 0 & 17 & 30 & 46 & 161 \\
\hline Married & $44 \pm 27$ & 0 & 24 & 39 & 59 & 175 \\
\hline Widowed & $33 \pm 20$ & 0 & 18 & 29 & 45 & 144 \\
\hline \multicolumn{7}{|c|}{ Daily death counts (No. of deaths) } \\
\hline Total & $10 \pm 5$ & 0 & 7 & 9 & 13 & 34 \\
\hline Age $<75$ years & $1 \pm 1$ & 0 & 0 & 1 & 2 & 8 \\
\hline Age $\geq 75$ years & $9 \pm 4$ & 0 & 6 & 8 & 11 & 33 \\
\hline Male & $6 \pm 3$ & 0 & 3 & 5 & 7 & 18 \\
\hline Female & $5 \pm 3$ & 0 & 3 & 4 & 6 & 20 \\
\hline Married & $5 \pm 3$ & 0 & 3 & 4 & 7 & 19 \\
\hline Widowed & $5 \pm 3$ & 0 & 3 & 5 & 7 & 20 \\
\hline
\end{tabular}

and 73.87, respectively. Similar pattern were showed for the associations between $\mathrm{PM}_{2.5}$ and $\mathrm{ER}$ of COPD deaths.

In two pollutants models, the estimates for associations with $\mathrm{PM}_{2.5}$ and $\mathrm{PM}_{10}$ did not change much when the gaseous pollutants $\mathrm{SO}_{2}$ or $\mathrm{NO}_{2}$ were added in the models. For instance, when $\mathrm{SO}_{2}$ was added in the model, $10 \mu \mathrm{g} / \mathrm{m}^{3}$ increasing of $\mathrm{PM}_{2.5}$ was significantly associated with 1.28 (95\%CI: 0.46, 2.11) person year increase in YLL.

The results of modifications of age, gender and marital status were summarized in Table 4 . When stratified by age, the associations were stronger in the elderly ( $\geq 75$ years) than the younger ( $<75$ years). In the elderly, a $10 \mu \mathrm{g} / \mathrm{m}^{3}$ increase in $\mathrm{PM}_{2.5}$ corresponded to $0.98(95 \% \mathrm{CI}: 0.42,1.54)$ years increase in YLL. For the younger, no significant effects were found.

For the modification of gender, the associations between female and male were not significant. For different marital status, the associations in the widowed showed an increased trend compared with the married ones, though the effect estimate of the married was well within the widowed ones..

Sensitivity analyses results showed that the estimations were stable based on the variations of the parameters in the models (Table S4).

Table 2 Spearman correlation between air pollutants and meteorological conditions in Ningbo, China, 2011-2015

\begin{tabular}{lllllll}
\hline & $\mathrm{PM}_{2.5}$ & $\mathrm{PM}_{10}$ & $\mathrm{SO}_{2}$ & $\mathrm{NO}_{2}$ & Temperature $\left({ }^{\circ} \mathrm{C}\right)$ & Relative humidity $(\%)$ \\
\hline $\mathrm{PM}_{2.5}$ & 1.00 & 0.95 & 0.78 & 0.76 & -0.47 & -0.28 \\
$\mathrm{PM}_{10}$ & 0.95 & 1.00 & 0.83 & 0.76 & -0.46 & -0.42 \\
$\mathrm{SO}_{2}$ & 0.78 & 0.83 & 1.00 & 0.79 & -0.57 & -0.42 \\
$\mathrm{NO}_{2}$ & 0.76 & 0.76 & 0.79 & 1.00 & -0.59 & -0.13 \\
Temperature $\left({ }^{\circ} \mathrm{C}\right)$ & -0.47 & -0.46 & -0.57 & -0.59 & 1.00 & 0.13 \\
Relative humidity (\%) & -0.28 & -0.42 & -0.42 & -0.13 & 0.13 & 1.00 \\
\hline
\end{tabular}



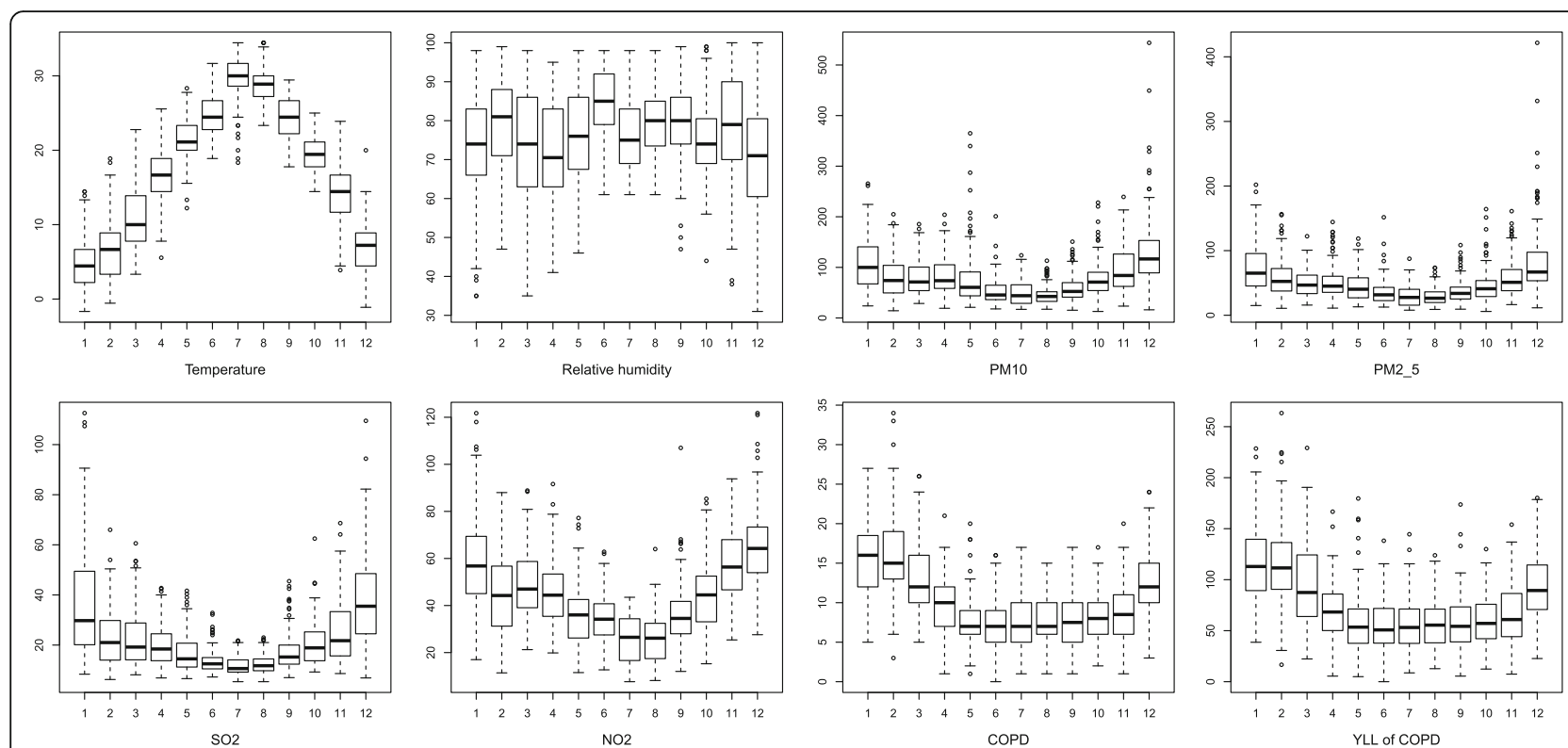

Fig. 1 Boxplots of monthly $\mathrm{PM}_{2.5}, \mathrm{PM}_{10}, \mathrm{SO}_{2}, \mathrm{NO}_{2}$, temperature, relative humidity, years of life lost, death counts of COPD and the corresponding YLL in Ningbo, China, 2011-2015

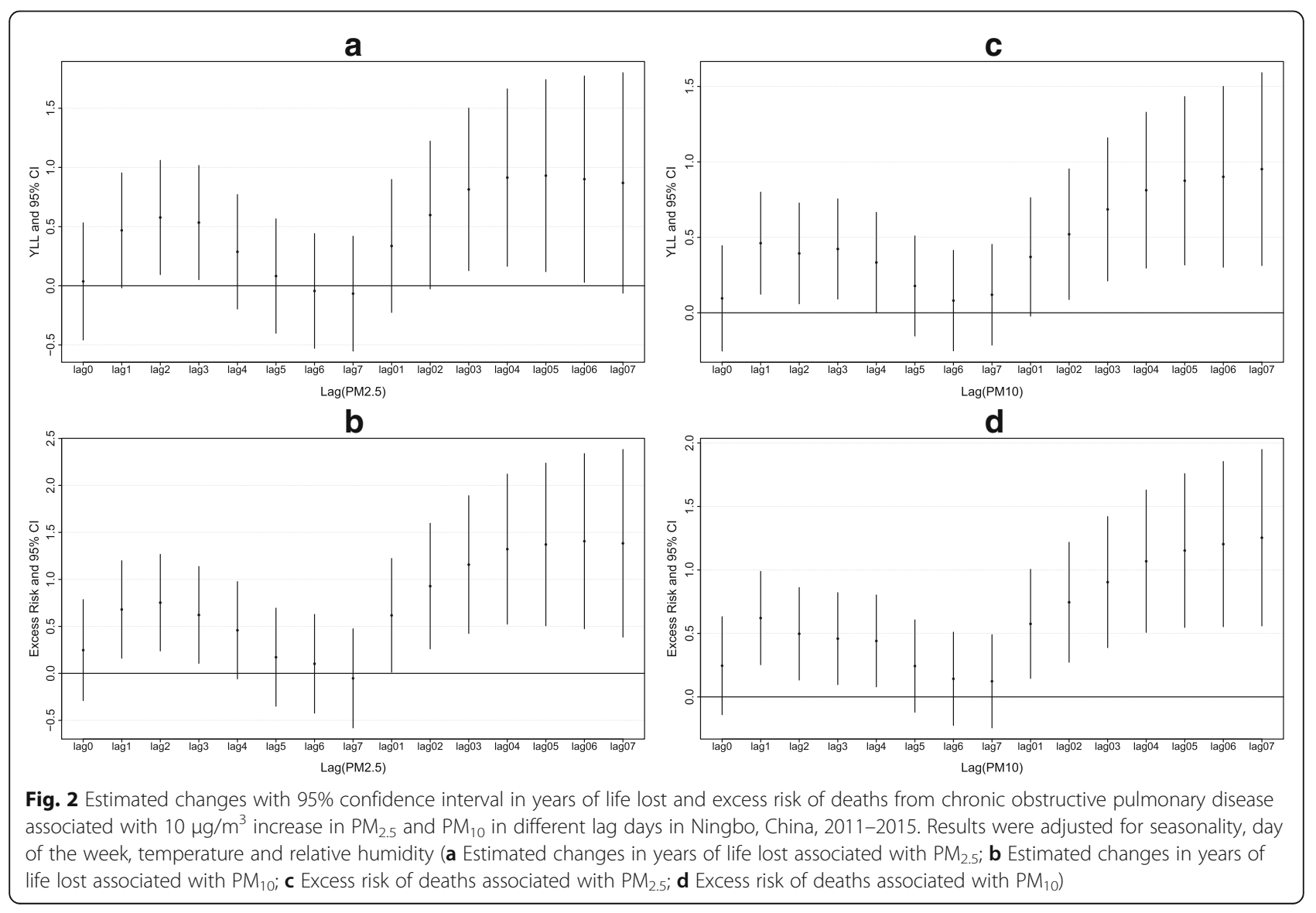




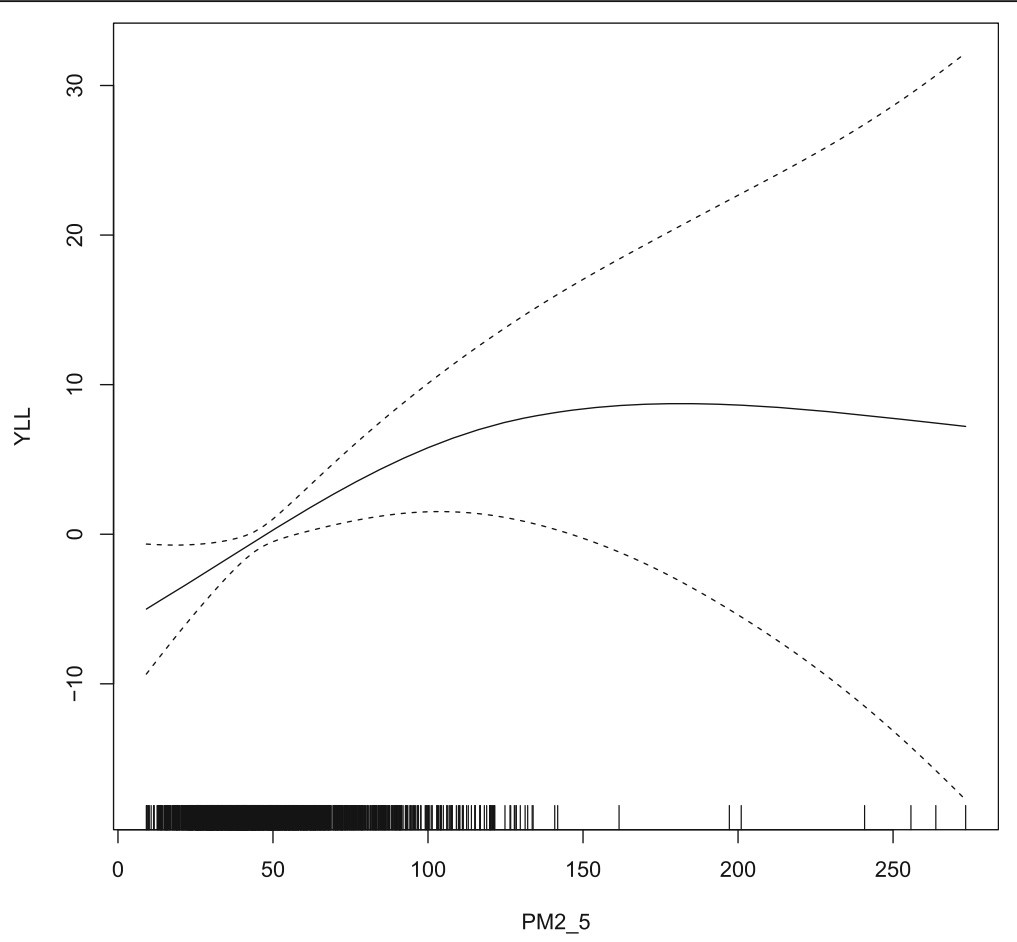

Fig. 3 Exposure-response curve of the levels of $\mathrm{PM}_{2.5}$ and years of life lost from COPD in Ningbo, China, 2011-2015

\section{Discussion}

The relationships between ambient $\mathrm{PM}_{2.5}$ and increased mortality risk were well documented [1-3]. Although previous studies indicated that $\mathrm{PM}_{2.5}$ is a significant environment trigger for acute exacerbation of COPD, and thus leading to increasing symptoms, emergency visits, hospital admissions and mortality [10-13]. A study conducted in China showed that $83 \%$ of the population lived in areas where $\mathrm{PM}_{2.5}$ concentrations exceeded the Chinese Ambient Air Quality Standard of $35 \mu \mathrm{g} / \mathrm{m}^{3}$, premature mortalities attributed to $\mathrm{PM}_{2.5}$ nationwide were 0.17 million for COPD [21]. However, the number of death ignores the difference in ages of deaths, and giving equal weights to the deaths occurring at a young age and those occurring at an old age. From a public health perspective, deaths occurring at different ages are not equally important, dying at a young age results in more potential years of life lost (YLL) [4, 6]. Nevertheless few studies using YLL as dependent variable to explore the health impact of the current exposure levels of $\mathrm{PM}_{2.5}$ on COPD deaths in China, possibly due to the lack of individual data needed for calculating YLL.

Our study explored the associations of $\mathrm{PM}_{2.5}$ exposure with daily YLL due to COPD for the first time. Based on the data of 18,472 COPD deaths over a five year period in Ningbo, China, we found that $\mathrm{PM}_{2.5}$ exposure were significant associated with increased YLL of COPD. Per $10 \mu \mathrm{g} / \mathrm{m}^{3}$ increase in $\mathrm{PM}_{2.5}$ was associated with 0.91(95\% CI: $0.16,1.66)$ years increase in YLL of COPD deaths. In the study of $\mathrm{He} 2016$ [5], an increase of $10 \mu \mathrm{g} / \mathrm{m}^{3}$ increase in $\mathrm{PM}_{2.5}$ was related to $2.97(95 \% \mathrm{CI}$ : $-2.01,7.95)$ years of all-cause mortality, which using the data of Ningbo from 2009 to 2013. The comparison showed the impact of $\mathrm{PM}_{2.5}$ on YLL from COPD and all-cause mortality is different, although the impact of $\mathrm{PM}_{2.5}$ on YLL of all-cause mortality was not significant, there was significant influence on COPD YLL. This indicated more investigations should be carried out to explore the impact of $\mathrm{PM}_{2.5}$ on YLL from diseases which are leading cause of death and disease burden such as COPD.

In addition, the excess YLL of COPD mortality was also estimated, which were 8206 years. Take the population in Ningbo into consideration, the YLL in days per person of the population for a 365 day period of exposure was nearly 0.38 day per person from 2011 to 2015, which gives a different perspective from excess death number.

Considering the indicator of YLL is a measure of disease burden that considers the life expectancy at death [6], and has been extensively used to identify and prioritize causes of premature death around the world [22], the results of our study provides a complementary indicator to that of excess deaths, and gives additional information for policy making and health resource allocation.

The exposure-response curve of $\mathrm{PM}_{2.5}$ and YLL due to COPD showed a non-linear pattern in Ningbo, 2011- 
Table 3 Associations of $10 \mu \mathrm{g} / \mathrm{m}^{3}$ increase in $\mathrm{PM}_{2.5}$ and $\mathrm{PM} 10$ with $\mathrm{YLL}$ and ER of deaths from COPD

\begin{tabular}{|c|c|c|}
\hline Pollutants and model & Years of life lost (95\% Cl) & Percentage increase in death $(95 \% \mathrm{Cl})$ \\
\hline \multicolumn{3}{|l|}{$\mathrm{PM}_{2.5}$ (Single model) } \\
\hline Total & $0.91(0.16,1.66)$ & $1.32(0.52,2.12)$ \\
\hline Low concentration level & $1.44(0.57,2.32)$ & $1.87(0.91,2.83)$ \\
\hline High concentration level & $0.32(-0.59,1.23)$ & $0.84(-0.10,1.79)$ \\
\hline \multicolumn{3}{|l|}{$\mathrm{PM}_{2.5}+\mathrm{SO}_{2}$} \\
\hline Total & $1.28(0.46,2.11)$ & $1.61(0.74,2.48)$ \\
\hline Low concentration level & $1.97(1.00,2.93)$ & $2.31(1.26,3.37)$ \\
\hline High concentration level & $0.65(-0.30,1.60)$ & $1.12(0.14,2.11)$ \\
\hline \multicolumn{3}{|l|}{$\mathrm{PM}_{2.5}+\mathrm{NO}_{2}$} \\
\hline Total & $1.07(0.22,1.91)$ & $1.53(0.64,2.42)$ \\
\hline Low concentration level & $1.45(0.45,2.44)$ & $1.98(0.97,3.03)$ \\
\hline High concentration level & $0.39(-0.59,1.36)$ & $0.99(-0.05,1.97)$ \\
\hline \multicolumn{3}{|l|}{$\mathrm{PM}_{10}$ (Single model) } \\
\hline Total & $0.81(0.30,1.33)$ & $1.07(0.51,1.63)$ \\
\hline Low concentration level & $1.09(0.52,1.66)$ & $1.34(0.71,1.98)$ \\
\hline High concentration level & $0.35(-0.31,1.01)$ & $0.72(0.03,1.41)$ \\
\hline \multicolumn{3}{|l|}{$\mathrm{PM}_{10}+\mathrm{SO}_{2}$} \\
\hline Total & $1.08(0.51,1.65)$ & $1.28(0.66,1.89)$ \\
\hline Low concentration level & $1.41(0.79,2.04)$ & $1.60(0.91,2.29)$ \\
\hline High concentration level & $0.59(-0.09,1.28)$ & $0.91(0.19,1.63)$ \\
\hline \multicolumn{3}{|l|}{$\mathrm{PM}_{10}+\mathrm{NO}_{2}$} \\
\hline Total & $0.96(0.38,1.55)$ & $1.26(0.63,1.89)$ \\
\hline Low concentration level & $1.18(0.53,1.83)$ & $1.51(0.82,2.17)$ \\
\hline High concentration level & $0.46(-0.25,1.17)$ & $0.85(1.01,1.63)$ \\
\hline
\end{tabular}

Associations in all concentrations and in low and high concentrations levels were both presented at lag04 (moving average concentrations from day 0 to day4). Single and two pollutants models were used. Data were collected from Ningbo, China, 2011-2015

2015. The curve was relatively steep at low levels and flattened out at higher exposures. Previous studies also found similar pattern under different levels of particulate matter [20, 23, 24]. However, considering there were few observations for $\mathrm{PM}_{2.5}$, cautions should be taken when using the estimations in the high concentration level.

In this study, we found that the associations of $\mathrm{PM}_{2.5}$ on both daily YLL and death counts of COPD were stronger in the elderly ( $\geq 75$ years) than the younger ( $<75$ years). The difference was plausible from a biological perspective because of the decreased immunologic function and reduced lung function as a natural part of aging, and frailty status which decrease physiologic reserve for the adverse effects of air pollution, etc. [25, 26]. In addition, elderly individuals frequently have pre-existing chronic diseases, which may make them more vulnerable to the adverse influence of particulate matter exposure $[27,28]$. The higher impact in the elderly was consistence with a previous study conduct in Ningbo which explored the air pollution-YLL relationships [5], while was different from the results from Beijing which indicated the influence of particulate matter on daily YLL was higher in the younger people [4]. Considering the annual concentrations of $\mathrm{PM}_{2.5}$ and $\mathrm{PM}_{10}$ were $105.1 \mu \mathrm{g} / \mathrm{m}^{3}$ and $144.6 \mu \mathrm{g} /$ $\mathrm{m}^{3}$ in the Beijing study, the difference may be due to the different levels of particulate matter in Beijing and

Table 4 Associations of $\mathrm{PM}_{2.5}$ with YLL and ER of COPD deaths stratified by age, gender and marital status

\begin{tabular}{|c|c|c|c|c|c|c|}
\hline \multirow[t]{2}{*}{ Indicator } & \multicolumn{2}{|l|}{ Age } & \multicolumn{2}{|l|}{ Gender } & \multicolumn{2}{|l|}{ Marital status } \\
\hline & $<75$ years & $\geq 75$ years & Male & Female & Married & Widowed \\
\hline Years of life lost (95\% Cl) & $-0.06(-0.54,0.42)$ & $0.98(0.42,1.54)^{*}$ & $0.47(-0.08,1.01)$ & $0.45(-0.04,0.94)$ & $0.27(-0.30,0.84)$ & $0.63(0.21,1.05)$ \\
\hline Percentage increase in death $(95 \% \mathrm{Cl})$ & $-0.05(-2.39,2.30)$ & $1.49(0.65,2.33)^{*}$ & $1.12(0.06,2.18)$ & $1.57(0.39,2.74)$ & $0.84(-0.31,2.00)$ & $1.76(0.66,2.86)$ \\
\hline
\end{tabular}

Associations were presented at lag04 (moving average concentrations from day 0 to day4) with $10 \mu \mathrm{g} / \mathrm{m}^{3}$ increase in PM 2.5 . Data were collected from Ningbo, China, 2011-2015. ${ }^{*} P<0.05$ 
Ningbo, which implied the associations of particulate matter and YLL would be different in various pollution levels.

For gender modification, although previous study indicated that female may be more susceptible to particulate matter pollution because female is a risk factor for developing airflow limitation and consequently COPD [29], furthermore, female with COPD would have worse prognosis due to more pronounced dyspnea, lower BMI, and more frequent anxiety [30], we did not found significant differences between gender.

It's the first time to explore the potential effect modification of marital status in the particulate matter exposure and YLL relationships, though non significance was found. Further investigations still need to be carried out in future.

In our study, we also evaluated the particulate matter exposure and ER of death counts in our study. Our results showed a $10 \mu \mathrm{g} / \mathrm{m}^{3}$ increase in $\mathrm{PM}_{2.5}$ and $\mathrm{PM}_{10}$ were associated with maximum increases in ER of death counts of 1.32\% (95\%CI: $0.52 \%, 2.12 \%$ ) and $1.07 \%$ (95\%CI: $0.51 \%$, $1.63 \%)$ at lag04, respectively. The results were supported by previous studies. For instance, meta-analysis of 31 studies showed that a $10 \mu \mathrm{g} / \mathrm{m}^{3}$ increase in $\mathrm{PM}_{10}$ was associated with increase in COPD mortality with an OR of 1.011 (95\%CI: 1.008, 1.014) [31]. A study conducted in Guangzhou also found an increase of $10 \mu \mathrm{g} / \mathrm{m}^{3}$ increase in $\mathrm{PM}_{10}$ was associated with $1.58 \%$ (95\%CI: $0.12 \%, 3.06 \%$ ) increase of COPD mortality [19].

This study has several strengths. First, our study explored the associations between $\mathrm{PM}_{2.5}$ exposure and YLL due to COPD for the first time, and the excess YLL were also calculated. Using YLL as a key indicator to measure the impact of particulate matter on premature deaths will provide more information for policy making and resources allocation. Secondly, exploring the exposure-response curve of $\mathrm{PM}_{2.5}$ on YLL due to COPD was the first time. We found the exposure-response curve was nonlinear and the associations were steeper in the low $\mathrm{PM}_{2.5}$ concentrations and became flattening in the high $\mathrm{PM}_{2.5}$ concentrations. Thirdly, the modification of socioeconomic factors especially the marital status was first investigated, and provided complementary information for identifying vulnerable subgroups.

However, the data used in the study were only from one city, and cautions should be taken when generalizing the results to other geographic areas. In addition, we used ambient particulate matter from fixed site rather than individual exposure, which may result in measurement error, and the individual risk factors such as smoking, drinking and underlying diseases were unknown and not controlled in the study. Furthermore, as we used time series method to estimate the effects which was considered inappropriate to estimate longterm effects [32], it should be careful when analysing the long-term associations.

\section{Conclusions}

In conclusion, our study provided a new insight into the disease burden due to COPD of ambient $\mathrm{PM}_{2.5}$ exposure. We found that $\mathrm{PM}_{2.5}$ had significant impacts on YLL due to COPD in Ningbo, China. Furthermore, the exposure-response curve was nonlinear and the associations were steeper at low levels and became flattened out at higher exposures. The elderly were susceptible population. Our findings highlight the importance and urgency of ambient $\mathrm{PM}_{2.5}$ control and protection of the vulnerable populations.

\section{Additional file}

Additional file 1: Table S1. Life expectancy for Chinese population (averaged value for 2011-2015). Table S2. Threshold selection based on the Akaike Information Criterion value. Table S3. Sensitivity analyses of associations of $\mathrm{PM}_{25}$ and $\mathrm{PM}_{10}$ with $\mathrm{YLL}$ and ER of COPD deaths. Figure S1. Distribution of daily deaths and daily YLL of COPD in Ningbo, 2011-2015, China. Figure S2. Auto-correlation function for residuals of $\mathrm{PM}_{2.5}$ single pollutant models for YLL of COPD at lag04. Figure S3. Auto-correlation function for residuals of $\mathrm{PM}_{2.5}$ single pollutant models for deaths of COPD at lag04. Figure S4. Auto-correlation function for residuals of $\mathrm{PM}_{10}$ single pollutant models for YLL of COPD at lag04. Figure S5. Auto-correlation function for residuals of $\mathrm{PM}_{10}$ single pollutant models for deaths of COPD at lag04. (DOCX $21 \mathrm{~kb}$ )

\section{Abbreviations}

ACF: Autocorrelation function; AIC: Akaike information criterion;

$\mathrm{Cl}$ : Confidence interval; COPD: Chronic obstructive pulmonary disease; ER: Excess risk; GAM: Generalized additive model; $\mathrm{NO}_{2}$ : Nitrogen dioxide; $\mathrm{PM}_{10}$ : Inhalable particulate matter; $\mathrm{PM}_{2.5}$ : Fine particulate matter; $\mathrm{SO}_{2}$ : Sulfur dioxide; WHO: World Health Organization; YLL: Years of life lost

\section{Acknowledgements}

We thank the Ningbo Municipal Center for Disease Control and Prevention and the Environment Monitoring Center of Ningbo for providing the health data and air pollution data, respectively. Moreover, we thank the Ningbo Meteorological Bureau for providing the meteorological data.

\section{Funding}

This work was supported by the National Natural Science Foundation of China (No. 81372950 and No. 81502780), the National Key Research and Development Program of China (No. 2016YFC0207103 \& No.

2016YFC0206506), Young Elite Scientists Sponsorship Program by the China Association for Science and Technology (No.2016QNRC001), the Medical Technology Program Foundation of Zhejiang, China (2014KYA202) and Science and Technology Program of Ningbo, China (No.2014C50027). The funders had no role in study design, data collection and analysis, decision to publish, or preparation of the manuscript.

\section{Availability of data and materials \\ Raw data of COPD mortality and daily air pollution concentrations were requested and obtained from Ningbo Municipal Center for Disease Control and Prevention and the Environment Monitoring Center of Ningbo, respectively. The raw meteorological data were obtained from the Ningbo Meteorological Bureau. Raw data will not be shared because the authors are not authorized for distribution of data.}

\section{Authors' contributions}

GL and $J H$ designed the study and developed the analysis plan. GL performed statistical analyses and took responsibility for the accuracy of the data analysis. $J \mathrm{H}$ wrote the manuscript. These two authors contributed equally to the study. GX gave suggestions for the implementation. XP gave advice for the statistical analysis. XQ collected the data. JX and TZ took responsibility for the integrity of the data. $Y Z$ conducted the literature review and QL helped prepare and 
method section. XG gave advice for the designation of the study. TH directed its implementation, reviewed and edited the manuscript. All authors contributed to the revision and approved the final manuscript.

\section{Competing interests}

The authors declare that they have no competing interests.

\section{Consent for publication}

Not applicable.

\section{Ethics approval and consent to participate}

The study was approved by the Institutional Review Board of Ningbo Municipal Center for Disease Control and Prevention (IRB 201603). Informed consent was not required because the data used in the study were deaths registration records and the data were anonymous.

\section{Publisher's Note}

Springer Nature remains neutral with regard to jurisdictional claims in published maps and institutional affiliations.

\section{Author details}

'Department of Occupational and Environmental Health Sciences, Peking University School of Public Health, 38 Xueyuan Road, Beijing 100191, China. ${ }^{2}$ Ningbo Municipal Center for Disease Control and Prevention, Haishu District, 237 Yongfeng Road, Ningbo 315010, China. ${ }^{3}$ Ningbo First Hospital, 59 Liuting Street, Ningbo 315010, China. ${ }^{4}$ Tulan University, 6823 St. Charles Avenue, New Orleans, LA 70118, USA.

Received: 10 December 2016 Accepted: 1 May 2017

Published online: 06 June 2017

\section{References}

1. Dai L, Zanobetti A, Koutrakis P, Schwartz JD. Associations of fine particulate matter species with mortality in the United States: a multicity time-series analysis. Environ Health Perspect. 2014;122:837-42.

2. Chen R, Kan H, Chen B, Huang W, Bai Z, Song G, Pan G. CAPES Collaborative Group. Association of particulate air pollution with daily mortality: the China Air Pollution and Health Effects Study. Am J Epidemiol. 2012;175:1173-81.

3. Shang Y, Sun Z, Cao J, Wang X, Zhong L, Bi X, et al. Systemic review of Chinese studies of short-term exposure to air pollution and daily mortality. Environ Int. 2013;54:100-11.

4. Guo Y, Li S, Tian Z, Pan X, Zhang J, Williams G. The burden of air pollution on years of life lost in Beijing, China, 2004-08: retrospective regression analysis of daily deaths. BMJ. 2013;347:f7139.

5. He T, Yang Z, Liu T, Shen Y, Fu X, Qian X, et al. Ambient air pollution and years of life lost in Ningbo, China. Sci Rep. 2016;6:22485.

6. Brustugun OT, Moller B, Helland A. Years of life lost as a measure of cancer burden on a national level. Br J Cancer. 2014;111:1014-20.

7. Global Initiative for Chronic Lung Disease (GOLD). Global strategy for diagnosis, management and prevention of chronic obstructive pulmonary disease. 2014.

8. Mannino DM. COPD: epidemiology, prevalence, morbidity and mortality, and disease heterogeneity. Chest. 2002;121:121S-6S.

9. Lozano R, Naghavi M, Foreman K, Lim S, Shibuya K, Aboyans V, et al. Global and regional mortality from 235 causes of death for 20 age groups in 1990 and 2010: a systematic analysis for the Global Burden of Disease Study 2010. Lancet. 2012;380:2095-128.

10. Bloemsma LD, Hoek G, Smit LA. Panel studies of air pollution in patients with COPD: systematic review and meta-analysis. Environ Res. 2016;151:458-68.

11. Karakatsani A, Analitis A, Perifanou D, Ayres JG, Harrison RM, Kotronarou A, et al. Particulate matter air pollution and respiratory symptoms in individuals having either asthma or chronic obstructive pulmonary disease: a European multicentre panel study. Environ Health. 2012;11:75.

12. Zhang S, Li G, Tian L, Guo Q, Pan X. Short-term exposure to air pollution and morbidity of COPD and asthma in East Asian area: a systematic review and meta-analysis. Environ Res. 2016;148:15-23.

13. To T, Zhu J, Larsen K, Simatovic J, Feldman L, Ryckman K, et al. Progression from asthma to chronic obstructive pulmonary disease. Is air pollution a risk factor? Am J Respir Crit Care Med. 2016;194:429-38.

14. Ministry of Environmental Protection of the People's Republic of China. Ambient air quality standards. GB 3095-2012. Beijing, China Environmental
Science Press. http://kjs.mep.gov.cn/hjbhbz/bzwb/dqhjbh/dqhjzlbz/201203/ t20120302 224165.htm. Accessed 3 June 2017.

15. Guo Y, Barnett AG, Pan X, Yu W, Tong S. The impact of temperature on mortality in Tianjin, China: a case-crossover design with a distributed lag nonlinear model. Environ Health Perspect. 2011;119:1719-25.

16. Liu T, Zhang YH, Xu YJ, Lin HJ, Xu XJ, Luo Y, et al. The effects of dust-haze on mortality are modified by seasons and individual characteristics in Guangzhou. China Environ Pollut. 2014;187:116-23.

17. Zeng $Q$, Ni Y, Jiang G, Li G, Pan X. The short term burden of ambient particulate matters on non-accidental mortality and years of life lost: a tenyear multi-district study in Tianjin. China Environ Pollut. 2017:220:713-9.

18. Yang J, Ou CQ, Song YF, Li L, Chen PY, Liu QY. Estimating years of life lost from cardiovascular mortality related to air pollution in Guangzhou, China. Sci Total Environ. 2016;S0048-9697:31931-3.

19. Li L, Yang J, Song YF, Chen PY, Ou CQ. The burden of COPD mortality due to ambient air pollution in Guangzhou, China. Sci Rep. 2016;6:25900.

20. Zeng Q, Li G, Zhao L, Jiang G, Pan X. Characteristics of the exposureresponse relationship of particulate matter and mortality: a time series analysis of 7 cities in China. J Occup Environ Med. 2015;57:e93-100.

21. Liu J, Han Y, Tang X, Zhu J, Zhu T. Estimating adult mortality attributable to $\mathrm{PM}_{2.5}$ exposure in China with assimilated $\mathrm{PM}_{2.5}$ concentrations based on a ground monitoring network. Sci Total Environ. 2016:568:1253-62.

22. Wang H, Dwyer-Lindgren L, Lofgren KT, Rajaratnam JK, Marcus JR, Levin-Rector A, et al. Age-specific and sex-specific mortality in 187 countries, 1970-2010: a systematic analysis for the Global Burden of Disease Study 2010. Lancet. 2012; 380:2071-94.

23. Pope CA 3rd, Burnett RT, Krewski D, Jerrett M, Shi Y, Calle E, et al. Cardiovascular mortality and exposure to airborne fine particulate matter and cigarette smoke: shape of the exposure-response relationship. Circulation. 2009;120:941-8.

24. Kan H, London SJ, Chen G, Zhang Y, Song G, Zhao N, et al. Differentiating the effects of fine and coarse particles on daily mortality in Shanghai, China. Environ Int. 2007:33:376-84.

25. Viegi G, Maio S, Simoni M, Baldacci S, Annesi-Maesano I. The epidemiological link between ageing and respiratory diseases. In: Bellia V, Incalzi RA, editors. european respiratory monograph 43: respiratory diseases in the elderly. Plymouth: European Respiratory Society; 2009. p. 1-17.

26. Eckel SP, Louis TA, Chaves PH, Fried LP, Margolis AH. Modification of the association between ambient air pollution and lung function by frailty status among older adults in the Cardiovascular Health Study. Am J Epidemiol. 2012;176:214-23.

27. Bateson TF, Schwartz J. Who is sensitive to the effects of particulate air pollution on mortality? A case-crossover analysis of effect modifiers. Epidemiology. 2004;15:143-9.

28. Goldberg MS, Burnett RT, Stieb DM, Brophy JM, Daskalopoulou SS, Valois $M F$, et al. Associations between ambient air pollution and daily mortality among elderly persons in Montreal, Quebec. Sci Total Environ. 2013:463464:931-42.

29. Luoto JA, Elmståhl S, Wollmer P, Pihlsgård M. Incidence of airflow limitation in subjects 65-100 years of age. Eur Respir J. 2016;47:461-72.

30. Roche N, Deslée G, Caillaud D, Brinchault G, Court-Fortune I, Nesme-Meyer P, Surpas P, Escamilla R, Perez T, Chanez P, Pinet C, Jebrak G, Paillasseur J Burgel PR, INITIATIVES BPCO Scientific Committee. Impact of gender on COPD expression in a real-life cohort. Respir Res. 2014;15:20.

31. Zhu R, Chen $Y$, Wu S, Deng F, Liu Y, Yao W. The relationship between particulate matter $\left(\mathrm{PM}_{10}\right)$ and hospitalizations and mortality of chronic obstructive pulmonary disease: a meta-analysis. COPD. 2013;10:307-15.

32. Michael AJ, Anderson HR, Brunekreef B, Cohen AJ. Inappropriate use of daily mortality analyses to estimate longer-term mortality effects of air pollution. Int J Epidemiol.1998:27(3):450-3. 